\title{
How safe are over the counter abortion pills-differences between its intended and practical usage and its implications - a study conducted in a tertiary care centre in Shillong, Meghalaya, India
}

\author{
Manika Agarwal ${ }^{1}$, Amrita Datta $^{2} *$ \\ ${ }^{1}$ Department of Obstetrics and Gynaecology, NEIGRIHMS, Shillong Meghalaya, India \\ ${ }^{2}$ Department of Obstetrics and Gynaecology, ANIIMS, Andaman and Nicober Islands, India
}

Received: 04 July 2016

Accepted: 05 August 2016

\section{*Correspondence:}

Dr. Amrita Datta,

E-mail: dr.amritadatta@gmail.com

Copyright: $\odot$ the author(s), publisher and licensee Medip Academy. This is an open-access article distributed under the terms of the Creative Commons Attribution Non-Commercial License, which permits unrestricted non-commercial use, distribution, and reproduction in any medium, provided the original work is properly cited.

\begin{abstract}
Background: MTP Act has been a boon in India with legalization of medical abortion. But its misuse by the rampant usage of over the counter medical abortifacients leads to complications. This study was done to gather data regarding the over the counter purchase and usage of medical abortifacients and its effect on women.

Methods: Retrospective analytical study conducted in NEIGRIHMS, Shillong during January-June 2015. Case-sheets of women who had medical abortifacients after purchasing them over the counter were analyzed. Data were obtained under: Age, parity, persons recommending medical abortifacients, gestational age at pill intake, medicines taken, patients taking medicines more than once in same pregnancy, interval between pill intake and hospital presentation, presenting complaints, co-morbidities, outcome following self-administration of medical abortifacients and management given. Data were tabulated, calculated.

Results: Out of 30 cases, primis were majority (33.33\%). Maximum pills popped on pharmacist's (73.33\%) recommendations. $76.66 \%$ of patients took the pills within 63 days of gestation. $30 \%$ could not recall their medicines and $23 \%$ took I-pills as abortifacients. $23.33 \%$ took repeat dose in same pregnancy. $43.33 \%$ presented within $5-10$ days of pill intake. Commonest presentation was irregular bleed and passage of fleshy mass with bleeding PV, $33.33 \%$. Anaemia was the commonest co-morbidity $(76.66 \%)$. Retained products were in $56.66 \% .70 \%$ managed by surgical evacuation alone, with blood transfusion in $10 \%$ of patients.

Conclusions: Over the counter purchase of medical abortifacients without proper knowledge causes unprecedented maternal morbidity and mortality. National bodies should impose strict legislations to stop this.
\end{abstract}

Keywords: Medical abortifacients, Over the counter, Unsafe abortion

\section{INTRODUCTION}

Medical abortion as defined by WHO is the "usage of pharmacological drugs to terminate pregnancy". The Indian Parliament passed the MTP Act in 1971 with the goal of regulating and ensuring access to safe abortion. ${ }^{2}$ But was only after 2002's Amendment that medical abortion using Mifepristone and Misoprostol has been approved as a legal method of termination of early pregnancy. ${ }^{3}$
WHO has documented clear guidelines about both early as well as $2^{\text {nd }}$ trimester abortions. FOGSI suggested protocol for early abortion up to 7 weeks since LMP are $200 \mathrm{mg}$ mifepristone followed after 36-48 hours by 400 $\mathrm{mcg}$ of oral/vaginal misoprostol or $800 \mathrm{mcg}$ of oral/vaginal misoprostol over 7 weeks. FOGSI guidelines also demand precise pre abortion examination; investigations etc. as also proper education of the women about the advantages, drawbacks, risks and limitations of the process with need for follow up. ${ }^{4}$ 
Under existing laws, medical methods can only administered by gynaecologists and registered medical practitioners for performing MTPs by the MTP act of 1971. In 2003, an amendment to the MTP rules and Regulations was passed to enable certified abortion providers to prescribe medical abortion drugs outside a registered setting as long as emergency facilities are available to them. ${ }^{5}$

Provisional Govt. figures estimate that 621,748 abortions were performed in 2011-12 which increased to 636, 306 in 2012-2013. In 2014, systematic analysis of worldwide data estimated that approximately $8 \%$ of all maternal deaths are attributable to unsafe abortions and related complications. Unsafe abortion is defined by WHO as a procedure for terminating an unwanted pregnancy either by persons lacking the necessary skills in an environment lacking minimal medical standards/both. Unsafe abortions in India is commonly carried out by women self-administering unapproved and typically ineffective drugs or taking approved drugs incorrectly often resulting in incomplete abortion and further complications. ${ }^{6}$ Lack of awareness about MTP Act and existing guidelines, concerns about privacy and affordability etc. lead women to choose medical abortifacients over the counter. Such abortions often culminate in haemorrhage, shock, sepsis and in extremes even death.

Govt. data exclude abortions completed using medical abortion pills sold without a prescription by drug sellers or pharmacists (who represent an important source of abortion services nowadays) and which may indirectly be adding to the unsafe abortion burden. ${ }^{6}$ Hence this study was an attempt to gather data regarding the rampant purchase of medical abortifacients over the counter without any medical supervision along with their effects in this part of the country as there was no related preexisting data.

\section{METHODS}

This is a retrospective analytical study conducted in NEIGRIHMS, Shillong during the time period JanuaryJune 2015 after taking permission from the hospital authorities. Study population compromise of women who had history of self-administration of medical abortifacients purchased over the counter and had presented to the hospital with complications. Data were collected under the following headings: age, parity, persons recommending medical abortifacients, gestational age at pill intake, medicines taken, number of patients taking medical abortifacients more than once in same pregnancy, interval between pill intake and presentation to the hospital, their presenting complaints, associated co-morbid conditions, outcome following selfadministration of medical abortifacients and management given to the patients. Data were tabulated and percentages were determined accordingly.

\section{RESULTS}

The total number of cases attending the hospital during the time from January - June 2015 was 30 . All of them had history of intake of medical abortifacients after buying them over the counter. All the women in our study were married by their own admission.

Table 1: The age/demographic profile of our patients.

\begin{tabular}{|lll|}
\hline Age group & Number of patients & Percentage \\
\hline $15-20$ & 5 & $16.66 \%$ \\
\hline $20-25$ & 8 & $26.66 \%$ \\
\hline $25-30$ & 8 & $26.66 \%$ \\
\hline $30-35$ & 6 & $20 \%$ \\
\hline $35-40$ & 3 & $10 \%$ \\
\hline
\end{tabular}

Table 2: Depicts parity of the study population.

\begin{tabular}{|lll|}
\hline Parity & Number of patients & Percentage \\
\hline Primi & 10 & $33.33 \%$ \\
\hline Gravida 2 & 4 & $13.33 \%$ \\
\hline Gravida 3 & 7 & $23.33 \%$ \\
\hline Gravida 4 and above & 9 & $30 \%$ \\
\hline
\end{tabular}

Table 3: Persons recommending pill intake.

\begin{tabular}{|lll|}
\hline People & Number & Percentage \\
\hline Pharmacists & 22 & $73.33 \%$ \\
\hline Family members & 3 & $10 \%$ \\
\hline Friends & 4 & $14 \%$ \\
\hline Social media & 1 & $3.33 \%$ \\
\hline
\end{tabular}

Table 4: Gestational age at pill intake.

\begin{tabular}{|lll|}
\hline Gestational age & Number & Percentage \\
\hline 5-7 weeks (35- 49 days) & 14 & $46.66 \%$ \\
\hline 7-9 weeks (49-63 days) & 9 & $30 \%$ \\
\hline 9-12 weeks (63-84 days) & 5 & $16.66 \%$ \\
\hline $12-15$ weeks or more & 2 & $6.66 \%$ \\
\hline
\end{tabular}

Table 5: Medicines purchased over the counter.

\begin{tabular}{|lll|}
\hline Medicines & Number & Percentage \\
\hline MTP kit & 3 & $10 \%$ \\
\hline I pill & 7 & $23 \%$ \\
\hline Only misoprostol & 5 & $16 \%$ \\
\hline Not known (cannot recall) & 15 & $50 \%$ \\
\hline
\end{tabular}

Table 6: Patients taking repeat doses of abortifacients (more than once in same pregnancy).

\begin{tabular}{|lll|}
\hline & Number & Percentage \\
\hline Taken & 7 & $23.33 \%$ \\
\hline Not taken & 23 & $76.66 \%$ \\
\hline
\end{tabular}


Table 7: Interval between pill intake and presentation to the hospital.

\begin{tabular}{|lll|}
\hline Days & Number & Percentage \\
\hline $1-5$ & 4 & $13.33 \%$ \\
\hline $5-10$ & 13 & $43.33 \%$ \\
\hline $10-15$ & 6 & $20 \%$ \\
\hline $15-20$ & - & - \\
\hline $20-25$ & 1 & $3.33 \%$ \\
\hline $25-30$ & 4 & $13.33 \%$ \\
\hline$>30$ & 2 & $6.66 \%$ \\
\hline
\end{tabular}

Table 8: Presenting complaints.

\begin{tabular}{|lll|}
\hline Complaints & Number & Percentage \\
\hline Irregular bleed & 10 & $33.33 \%$ \\
\hline $\begin{array}{l}\text { Increased bleeding per } \\
\text { vaginum }\end{array}$ & 7 & $23.33 \%$ \\
\hline $\begin{array}{l}\text { Bleeding PV with } \\
\text { abdominal pain }\end{array}$ & 2 & $6.66 \%$ \\
\hline $\begin{array}{l}\text { Passage of fleshy mass } \\
\text { with bleeding PV }\end{array}$ & 10 & $33.33 \%$ \\
\hline $\begin{array}{l}\text { Fever with pain abdomen } \\
\text { and irregular bleeding } \\
\text { PV }\end{array}$ & 1 & $3.33 \%$ \\
\hline
\end{tabular}

Table 9: Associated co-morbid conditions.

\begin{tabular}{|lll|}
\hline Co morbidity & Number & Percentage \\
\hline Anaemia & 23 & $76.66 \%$ \\
\hline Fibroid & 1 & $3.33 \%$ \\
\hline Post c/s & 3 & $10 \%$ \\
\hline Post myomectomy & 1 & $3.33 \%$ \\
\hline Hypertension & 1 & $3.33 \%$ \\
\hline Others (deranged LFT) & 1 & $3.33 \%$ \\
\hline
\end{tabular}

Table 10: USG findings (post admission).

\begin{tabular}{|lll|}
\hline $\begin{array}{l}\text { Findings } \\
\text { F/s/o retained } \\
\text { products(including } \\
\text { incomplete abortion) }\end{array}$ & 17 & $56.66 \%$ \\
\hline $\begin{array}{l}\text { F/s/o missed abortion } \\
\text { F/s/o normal intrauterine } \\
\text { pregnancy }\end{array}$ & 9 & $30 \%$ \\
\hline F/s/o complete abortion & 2 & $6.66 \%$ \\
\hline
\end{tabular}

Table 11: Management given to the patients.

\begin{tabular}{|lll|}
\hline Treatment & Number & Percentage \\
\hline Medical management & 4 & $13.33 \%$ \\
\hline Surgical evacuation & 21 & $70 \%$ \\
\hline $\begin{array}{l}\text { Surgical evacuation with } \\
\text { blood transfusion }\end{array}$ & 3 & $10 \%$ \\
\hline $\begin{array}{l}\text { No treatment } \\
\text { (conservative) }\end{array}$ & 2 & $6.66 \%$ \\
\hline
\end{tabular}

Medical management was given with vaginal Misoprost tablets in patients having minimal retained products.

\section{DISCUSSION}

In our study, all the cases were married by their own admission. This is an important revelation as the potential of self-administering the medical abortifacients by unmarried women is quite high because of the stigma associated with unwed mothers in our society.

As seen in our study, most of the pill takers were in the age group 20-30 (around 52\%) showing that the young age groups were more likely to be influenced by inadvertent advice leading to rampant pill consumption. They were married but not prepared for a child and were open to resorts like over the counter medical abortifacients for easy solution. This is thought provoking as it could lead to more unhealthy reproductive practices in an age group of high fertility and reproductive potential. Contraception should be encouraged in place of quick fixes in the form of such drugs.

Primis $(33.33 \%)$ constituted majority of the pill poppers followed by $4^{\text {th }}$ and higher order gravidas $(23.33 \%)$ in our study, the reason could be due to unplanned pregnancy. Fast and hassle free is the image associated with over the counter medications which probably prompts them to resort to these for abortion.

We found that $73 \%$ of the persons recommending the medications are pharmacists. Under MTP Amendment Act, pharmacists are only supposed to sell medical abortifacients by prescription. But it doesn't happen always. There was neither prior counseling nor consent taking in all the cases which is very dangerous and against the protocol. As over the counter buying is an easy way to get hold of the abortifacients it needs to be stopped as it can lead to deleterious effects.

Most of the study population had taken the medical abortifacients within 63 days $(76 \%)$ which is within the recommended protocol. Late $1^{\text {st }}$ trimester and $2^{\text {nd }}$ trimester even though less percentages in our study were taken unsupervised this is dangerous. People are not aware of the recommended protocols which indirectly accounts for unsafe abortion in later stages. Generally risk of complications associated with all forms of abortion increases with gestational age rising exponentially after $1^{\text {st }}$ trimester even when terminations are performed under the best of circumstances.?

Our study pointed out maximum of pill takers were still confused about emergency contraceptives and medical abortifacients and they were used interchangeably leading to a lot of complications. This is other sense also means a defeat of the very purpose of medical abortifacients.

In our study, $23 \%$ of total study population took repeat dosing of these drugs in the same pregnancy. Most of the 
people were not even aware of the adequate dosing of medical abortifacients. As they were not properly counselled, many of them had not taken optimum dosage of the prescribed pills, and thinking that the present dosage did not work, many resorted to taking the medicines over again, which proved hazardous. This shows the plight of affairs that the patients do not receive proper counseling before taking over the counter medical abortifacients and did not know what to wait for.

Majority of patients in our study $(43.33 \%)$ attended the hospital within 5-10 days of abortifacient intake. Sometimes they even attended after 1 month (6.66\%). None of them were properly told about the procedure e.g. expected duration of bleeding, complications, day of follow up visit etc. and hence the disparity.

About $33.33 \%$ of patients had irregular bleeding pv as the presenting feature of our study while another $33.33 \%$ had complaints of fleshy mass passage along with bleeding pv. ${ }^{1}$ patient had features of septic abortion making a percentage of $3.33 \%$.Complications like infections, sepsis were common in women undergoing unsafe abortions. ${ }^{6}$

The main co-morbid condition found in our study was anaemia seen in $76.66 \%$ of patients which itself complicates many abortions. This is comparable to a study by Giri et al where $79 \%$ of women had varying degrees of anaemia following self-administration of medical abortifacients. ${ }^{8}$ Post $\mathrm{C} / \mathrm{S}$ patients constituted $10 \%$ of our total study population. According to a study by Potdar $\mathrm{J}$, the incidence of uterine rupture of a prior CS scar during medical abortion in early pregnancy was 3 in 768. ${ }^{9}$ There is a documented risk of $0.28 \%$ in $2^{\text {nd }}$ trimester abortion with prior caesarean delivery, and without prior caesarean delivery was $0.04 \% .{ }^{10}$ All the post $\mathrm{C} / \mathrm{S}$ patients in our study had taken medication without prior medical consultation which is a risky preposition.

USG findings in $56 \%$ of the patients in our study showed retained products of conception and 30\% had missed abortion which was a significant number. $6.66 \%$ had normal intrauterine pregnancy which was an evidence of drug failure. Ideally any method of medical abortion has an ongoing pregnancy rate of less than $1 \% .^{11}$

Incomplete abortion following medical abortifacient intake was seen in majority of the patients and surgical evacuation was done in $70 \%$ of the study population. This is similar to a study by Rajal VT et al where surgical curettage was required in $75.6 \%$ of patients. ${ }^{12}$ In medical abortion practice, method failure is considered to occur when a woman needs a surgical evacuation to complete the abortion for any reason (including incomplete abortion, viable pregnancy, hemorrhage, and patient request). Approximately $2-10 \%$ of women who have a medical abortion will need surgical aspiration. ${ }^{13}$ So, surgical evacuation could actually mean failure of medical evacuation which defeats the very purpose of medical abortifacients intake. In our study $10 \%$ of patients required blood transfusion along with surgical evacuation. Haemorrhage requiring transfusions occur in only about 1 in 1000 cases of medical abortions when the drugs are given under medical supervision. ${ }^{14}$

\section{CONCLUSION}

Surprising fact that came up in our study was the fact that most married primis were resorting to over the counter medical abortifacients symbolising faulty contraceptive habits. It would be wise if we educate and counsel the patients about proper contraceptive usage. Another salient feature was the confusion prevalent in general public between medical abortifacients and emergency contraception. Even if majority of these abortifacients were prescribed by the pharmacists they themselves did not have proper knowledge about these drugs nor did they counsel the patients either about anything. The poor women did not know what to expect which is a very dangerous preposition. This study gives an insight as to how the over the counter purchase of abortifacients is becoming rampant. Though there are guidelines and recommendations laid down by FOGSI and WHO, they are either not put to practise or very loosely followed taking everything for granted. National bodies can impose strict legislations on the over the counter purchase of abortifacients so as to make such selling a punishable offence.

Main limitation of this study is the small sample size. In future more studies with extensive data will come up which will help to quantify the real magnitude of the problem. Till then this is just a small step forward.

\section{ACKNOWLEDGEMENTS}

Authors would like to sincerely thank the staff of the Medical Record Section, NEIGRIHMS for helping us to collect the data.

Funding: No funding sources Conflict of interest: None declared

Ethical approval: Not required

\section{REFERENCES}

1. World Health Organization. Safe abortion: technical and policy guidelines for health systems. Second edition. 2012;6.

2. Government of India. The Medical Termination of Pregnancy Act, No. 34; 1971.

3. Government of India. The Medical Termination of Pregnancy Rules (Amendment); 2002.

4. FOGSI ICOG good clinical practice recommendations medical termination of pregnancy. Available at medind.nic.in/jaq/t11/ i1/jaqt11i1p90.pdf.

5. Government of India. The Medical Termination of Pregnancy Rules (Amendment); 2003. 
6. Stillman M, Frost JJ, Singh S, Ann MM, Kalyanwala S. Abortion in India: a literature review. New York: Guttmacher Institute; 2014:12-14.

7. Bartlett LA, Berg CJ, Shulman HB, Zane SB, Green CA, Whitehead S, et al. Risk factors for legal induced abortion-related mortality in the United States. Obstet Gynecol. 2004;103(4):729-37.

8. Giri A, Srivastav VR, Suwal A, Sharma B. A study of complications following self-administration with medical abortion pills. NJOG. 2015;19(1):20-4.

9. Potdar J. Medical abortion with mifepristone Misoprostol in previous caesarean section up to seven weeks gestation-a retrospective analysis of Dat. IJSR. 2013;2(3):330-1.

10. Goyal V. Uterine rupture in second trimester pregnancy termination in women with a prior caesarean delivery: a systematic review. Obstet Gynecol. 2009;113:1117-23.
11. International consensus conference on non-surgical (medical) abortion in early first trimester on issues related to regimens and service delivery, 2006. Frequently asked clinical questions about medical abortion. Geneva: World Health Organization. Available at. http://whqlibdoc.who.int/publications/ 2006/92415948 45_eng.pdf.

12. Rajal VT, Kruti JD, Parul TS. Self-medication of abortion pill: women's health in Jeopardy. NHLJMS. 2014;3:26-31.

13. Kruse B, Poppema S, Creinin M, Paul M. Management of side effects and complications in medical abortion. Am J Obstet Gynecol. 2000;183:S65-75.

14. Grimes DA. Medical abortions in early pregnancy: a review of the evidence. Obst Gynecol. 1997;89:7906.

Cite this article as: Agarwal M, Datta A. How safe are over the counter abortion pills-differences between its intended and practical usage and its implications - a study conducted in a tertiary care centre in Shillong, Meghalaya, India. Int J Reprod Contracept Obstet Gynecol 2016;5:3036-40. 